\title{
PROBLEMY TEKSTUALNE, EGZEGETYCZNE I TRANSLATORSKIE SO 3,18
}

Katolicki Komentarz Biblijny opisuje So 3,18 tylko jednym zdaniem: „Werset bezpowrotnie skażony". ${ }^{.}$Opinia ta nie jest odosobniona. Według A. Berlin, ,werset ten jest niezrozumiały”. ${ }^{2}$ Sweeney uważa, że to jedno z najtrudniejszych miejsc Księgi Sofoniasza. ${ }^{3}$ Dietrich pisze o niezrozumiałych słowach wersetu, prawdopodobnie skażonych. ${ }^{4}$ Skalę trudności trafnie opisuje również Hadjiev, zwracając uwagę, że w dwóch ostatnich komentarzach do Księgi Sofoniasza, zarówno Vlaardingerbroek jak i Perlitt zrezygnowali z jakiejkolwiek propozycji tłumaczenia tego wersetu. ${ }^{5}$

1 T.P. W a h 1, Księga Sofoniasza, w: R.E. B row n, J.A. F it z m y e r, R.E. M u r p h y (red.), Katolicki Komentarz Biblijny, Prymasowska Seria Biblijna 17, Warszawa 2001, s. 867.

2 „This verse is unintelligible”; A. B e r 1 i n, Zephaniah. A New Translation with Introduction and Commentary, Anchor Yale Bible 25A, New Haven-London 2008, s. 145.

3 ,V. 18 is one of the most difficult statements in the book of Zephaniah"; M.A. S w e e n e y, Zephaniah, Hermeneia - A Critical and Historical Commentary on the Bible, Minneapolis 2003, s. 203.

4 „Der Text ist nicht in jedem Wort leicht verstehbar, wohl auch etwas beschädigt"; W. D i e tr i c h, Die Kontexte des Zefanjabuches, w: W. D i e t r i c h, M. S c h w a n t e s (red.), Der Tag wird kommen. Ein intertextuelles Gespräch über das Buch des Prohpeten Zefanja, Stuttgarter Bibelstudien 170, Stuttgart 1996, s. 20 , n. 3 .

„The difficulties in Zephaniah 3,18 have long been recognized. An eloquent testimony to the challenges it presents to the interpreter is the fact that two of the most recent commentaries on Zephaniah decline to offer a meaningful translation of this verse"; T.S. H a d j i e v, The Translation Problems of Zephaniah 3,18: A Diachronic Solution, Zeitschrift für die alttestamentliche Wissenschaft 124/2012, s. 416. 
Celem artykułu jest szczegółowa analiza So 3,18. Przyjrzymy się kontekstowi So 3,18, manuskryptom hebrajskim oraz wersjom antycznym. Zostaną zaprezentowane rozwiązania, które ingerują w tekst, nie ingerują w tekst, ale są zależne od semantyki, od syntaksy oraz rozwiązanie diachroniczne.

\section{Kontekst So 3,18}

Interesujący nas werset znajduje się na końcu zarówno trzeciego rozdziału jak i całej Księgi Sofoniasza. Wielu komentatorów uważa Sof 3,9-20 za końcową sekcję księgi, sekcję, której tematem jest obietnica zbawienia. ${ }^{6}$ Sekcja składa się z mniejszych jednostek, które dzielone są w różny sposób. Wahl zalicza w. 18 do ostatniej z pięciu jednostek (ww. 18-20) i tytułuje ją: Wyrocznia: odmiana losu. ${ }^{7}$ Vlaardingerbroek dzieli tę sekcję również na pięć jednostek, jednak w. 18 zalicza do części przedostatniej (ww. 16-18) tytułując ją: Obietnica chwały dla Jeruzalem i powrotu rozproszonych. ${ }^{8}$ Irsigler dzieli cała sekcję na dwie główne podsekcje (ww. 9-13 i 14-20). Druga podsekcja dzieli się na mniejsze jednostki, z tym że część w. 18 przynależy do jednostki obejmującej ww. 3,16-18', natomiast pozostała część wersetu do jednostki ww. 3,18a-20. ${ }^{9}$ Spreafico widzi ostatnią sekcję Księgi Sofoniasza w ww. 6-20, które ze swej strony dzielą się na cztery jednostki. Ostatnią jednostką są ww. 18-20 mówiące o powrocie rozproszonych. ${ }^{10}$ Dla Mendeckiego ostatnią sekcją księgi jest

6 Por. T.P. W a h 1, Księga Sofoniasza, s. 864; J. V 1 a a r d i n g e r b r o e k, Zephaniah, Historical Commentary on the Old Testament, Leuven 1999, s. VI; H. I r s i g l e r, Zefanja, Herders Theologischer Kommentar zum Alten Testament, Freiburg-Basel-Wien 2002, s. 10-11.

7 Por. T.P. W a h 1, Księga Sofoniasza, s. 864.

8 Por. J. V la ard ing e r bro e k, Zephaniah, s. VI.

9 Por. H. Irsigl e r, Zefanja, s. 11, 363-364.

10 Por. A. S p r e a f i c o, Sofonia, Commentario storico ed esegetico all'Antico e al Nuovo Tesatmento 38, Genova 1991, s. 6. 
So 3, 9-15, natomiast ww. 16-20 byłyby uzupełnieniem obietnic dla Izraela. ${ }^{11}$ Jeszcze inaczej dzielą tekst Sweeney i Berlin, uważając ww. 14-20 za ostatnią i niepodzieloną na mniejsze jednostki sekcję księgi. ${ }^{12}$ Również Smith widzi w ww. 14-20 ostatnią sekcję księgi, jednak dzieli ją na pięć mniejszych jednostek, z czego ostatnią stanowią ww. 18-20, mówiące o obietnicy powrotu odrzuconych. ${ }^{13}$

Mimo rozbieżności w propozycjach budowy Księgi Sofoniasza, panuje dosyć wspólne przekonanie, że ww. 14-20 stanowią pewną całość.

${ }^{14}$ Wyśpiewuj, Córo Syjońska! Podnieś radosny okrzyk, Izraelu! Ciesz się i wesel z całego serca, Córo Jeruzalem!

${ }^{15}$ Oddalił Pan wyroki na ciebie, usunął twego nieprzyjaciela; Król Izraela, Pan, jest pośród ciebie, nie będziesz już bała się złego.

${ }^{16}$ Owego dnia powiedzą Jerozolimie: «Nie bój się, Syjonie! Niech nie słabną twe ręce!»

${ }^{17}$ Pan, twój Bóg, jest pośród ciebie, Mocarz, który zbawia, uniesie się weselem nad tobą, odnowi cię swoją miłością, wzniesie okrzyk radości.

${ }_{18}$ Pozbawionych świąt zgromadzę, bo do ciebie należeli. Ciężary nakładane na nią - hańbą.

${ }^{19}$ Oto Ja dokonam z a g ł a d y wszystkich, którzy cię uciskali w owym czasie, a zachowam chromych i wygnanych zgromadzę; i uczynię z nich chwałę i sławę na całej ziemi, gdzie zaznali wstydu.

${ }^{20} \mathrm{~W}$ owym czasie was przywiodę, a będzie to $\mathrm{w}$ czasie, gdy was zgromadzę; albowiem dam wam imię i chwałę

11 Por. N. M e n d e c k i, Koniec utrapień - wywyższenie dla Izraela u Sof 3,18-20, Collectanea Theologica 53/1983, s. 53-59.

12 Por. M.A. S w e e n e y, Zephaniah, s. VII, 193; A. B e r 1 i n, Zephaniah, s. 6-7.

13 Por. R.L. S m it h, Micah-Malachi, Word Biblical Commentary 32, Dallas 1998, s. 144. 
u wszystkich narodów ziemi, gdy odmienię wasz los na waszych oczach - mówi Pan” (BT, wyd. 5).

Wiersze 14-17 są czytelne. Najpierw autor zachęca Jerozolimę do radosnego śpiewu (w. 14). Następnie podaje przyczynę radości, którą jest usunięcie wrogów (w. 15) oraz prezentuje przyszłość Jerozolimy, w której obecny jest Bóg (w. 16-17). Tutaj mogłaby się kończyć cała Księga Sofoniasza i tak proponuje BHS, intepretując ww. 18-20 jako późniejszy dodatek. ${ }^{14}$ Wiersze $18-20$ przedstawiają bowiem sytuację tak, jakby jeszcze nie wszystko było odnowione i jakby wrogowie nie zostali usunięci, chociaż o usunięciu ich mówił w. 15. Gdyby usunąć tylko w. 18, a zachować ww. 19-20, logika byłaby następująca: cieszcie się, bo Bóg usunął wrogów Jerozolimy (ww. 14-17) i w przyszłości uczyni to samo, jeśli będzie trzeba (ww. 19-20).

Czy w. 18 albo ww. 18-20 były częścią pierwszej wersji Księgi Sofoniasza, nie dowiemy się nigdy. Wiemy jednak, że w. 18 należy czytać w kontekście uwolnienia Jerozolimy od wrogów, zapowiedzi jej sławy, zapewnienia Boga o Jego obecności i zmianie losu na lepsze uciśnionych i wygnańców.

\section{Sytuacja tekstualna So 3,18}

\section{Manuskrypty hebrajskie}

Tekst hebrajski w. 18 wg BHS brzmi następująco:

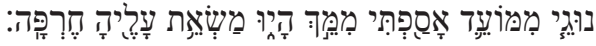

Dosłownie werset ten można tłumaczyć:

„Zasmuconych ze spotkania zbiorę od ciebie byli brzemieniem na niej hańby". ${ }^{15}$

14 Por. K. E11 ig e r, W. R u d olph (red.), Biblia Hebraica Stuttgartensia, Stuttgart 19975, s. 1059 (dalej tekście: BHS).

15 M. S z majdziń s k i tłumaczy literalnie: „Smutek ze spotkania zbiorę od ciebie (które) było brzmieniem na niej hańby"; t e n ż e, Księga Sofoniasza" 
Manuskrypt K 96 (z XIV w.) opuszcza דָּ, przez co werset staje się trochę mniej zagmatwany: „Zasmuconych ze spotkania zbiorę od ciebie brzemię na niej hańby".

Ponad 10 manuskryptów ${ }^{16}$ oraz dwie edycje Biblii Hebrajskiej ${ }^{17}$

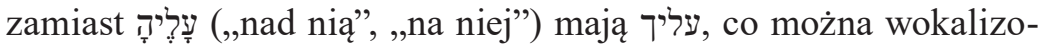

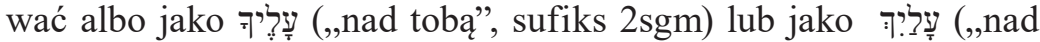

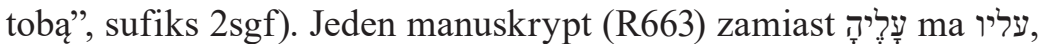

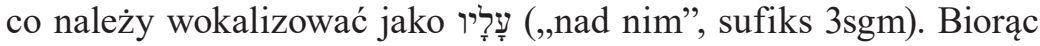

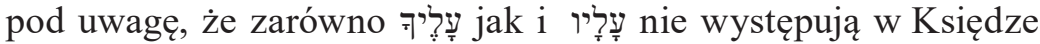

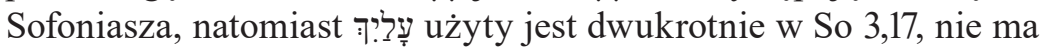
raczej wątpliwości, że lekcja עליך jest próbą harmonizacji w. 18 zarówno z w. 17 jak i z sufiksem מְִּ̣ znajdującym się w tym samym wersecie. Po zmianie werset można oddać jako: „Zasmuconych ze spotkania zbiorę od ciebie byli brzemieniem hańby na tobie". Wersja עליד jest lectio facilior i należy ją odrzucić, a nawet gdyby ją przyjąć,

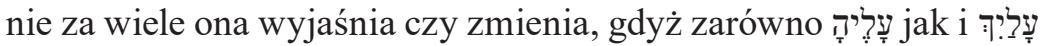
odnoszą się w najbliższym kontekście do Jerozolimy.

\section{Wersje antyczne}

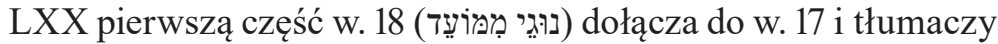
następująco:

w: A. K u ś m i r e k (oprac.), Hebrajsko-polski Stary Testament. Prorocy, Prymasowska Seria Biblijna 27, Warszawa 2008, s. 1519.

16 Są to K30 (1200 r.], K101 (XIV w.), K150 (XIII w.), K153 (1211 r.), K155 (XIII w.), K172 (XIV w.), K198 na marginesie (1291 r.), K224 (XII w.); R174 (XIII w.), R226 (XII w.), R380 (1296 r.), R545 (XIII w.), R554 (XIII w.), por. B. K e n n i c o t t, Vetus Testamentum hebraicum cum variis lectionibus, t. II, Oxonii 1780, s. 288; J.B. D e R o s s i, Variae lectiones Veteris Testamenti ex immensa Mss. editorumq. codicum congerie haustae et ad samar. textum, ad vetustiss. versiones, ad accuratiores sacrae criticae fontes ac leges examinatae, t. III, Parmae 1786 s. 209; t e n ż e, Scholia critica in V.T. Libros, Parmae 1798, s. 92.

17 Biblia Venetiis z 1518 r. oraz Biblia Halae-Michaelis z 1720 r. 


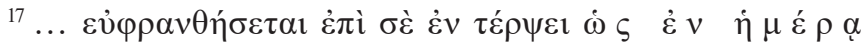
$\dot{\varepsilon}$ o $\rho \tau \tilde{\eta} \varsigma$.

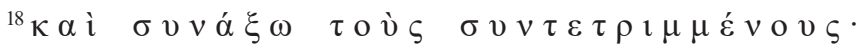

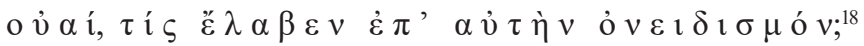

W tłumaczeniu Popowskiego ten fragment brzmi „... rozweseli się przy tobie szczęściem jak w dniu świątecznym. Ugoszczę zgnębionych. Biada temu, kto skierował przeciw niej obelgę!"'19.

Wyrażenie $\hat{\omega} \zeta \dot{\varepsilon} v \dot{\eta} \mu \varepsilon \dot{\varepsilon} \rho \alpha \underline{\varepsilon} 0 \rho \tau \tilde{\eta} \varsigma$ powstało najprawdopodobniej

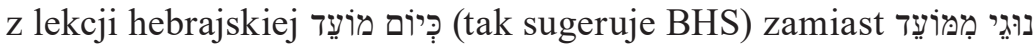
(tak jest w TM).

Kilkanaście manuskryptów greckich, Grzegorz z Nazjanzu i Teo-

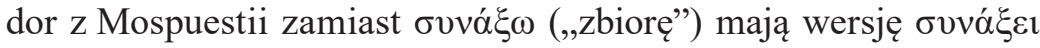
(,zbierze”). 3sgm mają również przekłady arabskie.

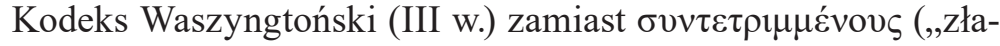
manych”, ,przygnębionych”, ,zmiażdżonych”) ma $\delta 1 \varepsilon \sigma \kappa o \rho \pi 1 \sigma \mu \varepsilon ́ v o v \varsigma$ (,rozrzuconych”, „rozproszonych”).

Akwila zamiast ov̉aí ma $\omega$, oba słowa znaczą biada. ${ }^{20}$ Różnica między „byli” (TM) a „biada” (LXX) wynika z wokalizacji oraz

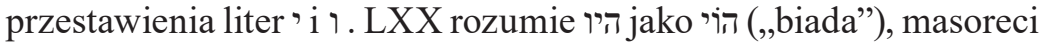
jako דָיוּ (,byli”).

18 Por. A. R a h 1 f s, Septuaginta, Stuttgart 1979, t. II, s. 541; J. Z i e g 1 e r (red.), Duodecim Prophetae, Vetus Testamentum Graecum. Auctoritate Academiae Scientiarum Gottingensis editum 13, Göttingen 1984, s. 284.

19 Por. R. P o p o w s k i, Septuaginta, Prymasowska Seria Biblijna 37, Warszawa 2013, s. 1349. Zaimek „niej” wskazuje na Jerozolimę. Zob. również tłumacznie Howarda "... and he will be glad over you with delight as on a day of a feast. And I will gather those who are shattered. Alas, who took up a reproach against her?"; G.E. H ow a r d, Sophonias, w: A. P i e t e r s m a, B. G. Wrig h t (red.), A New English Translation of the Septuagint and the Other Greek Translations Traditionally Included under that Title, Oxford 2007, s. 813.

${ }^{20} \mathrm{~W}$ tekście greckim Sofoniasza ov̉aì występuje w So 2,5: „Biada [oủai] zamieszkującym wybrzeże morskie - narodowi Kreteńczyków!”, natomiast $\tilde{\omega}$ w Sof

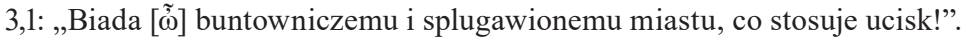

${ }^{21}$ BHS próbuje zrekonstruować tekst hebrajski, opierając się na LXX, dlatego proponuje czytać הוֹי מִי נָשָׁה עליה zamiast היו משאת עליה. 
Wulgata tłumaczy: „Nugas qui a lege recesserant congregabo quia ex te erant ut non ultra habeas super eis obprobrium", 22 co najlepiej oddało tłumaczenie Jakuba Wujka: „Plotki, którzy byli od zakonu byli odstąpili, zgromadzę, bo z ciebie byli, abyś więcej z nich nie miał urągania”. Początkowe נוּגו Wulgata tłumaczy przez nugas (acc. pl od nugat - ,paplanina”, „brednie”, ,plotki”). Natomiast מוֹעֵ rozumie jako ,prawo" (lex). ${ }^{23}$

Targum ma następującą wersję: Wg BW10:

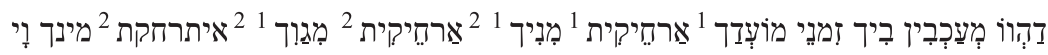

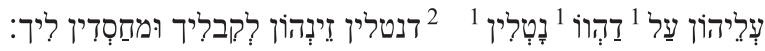

Wg Vlaardingerbroeka:

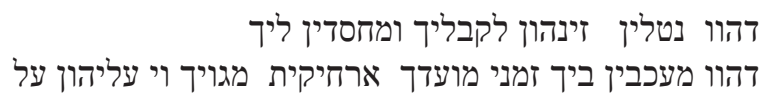

„Ci, którzy pośród ciebie opóźniali czasy twoich świąt. Usunąłem ich spośród ciebie. Biada im, bo podnieśli broń przeciw tobie i wstyd ci przynieśli". ${ }^{24}$

22 R. W e b e r, R. G r y s o n (red.), Biblia Sacra iuxta Vulgatam versionem, Stuttgart 19944.

${ }^{23}$ Neowulgata idzie raczej za LXX: ,... sicut in die conventus. Auferam a te calamitatem, ut non ultra habeas super ea opprobrium", Nova Vulgata. Bibliorum Sanctorum, Roma 19862, s. 1733.

24 "Those who among you delayed the times of your feasts. I have removed from your midst; woe betide them, because they carried their weapons against you and brought shame upon you"; cyt. za: J. V l a a r d i n ge r b r o e k, Zephaniah, s. 211. Zob. również tłumaczenie K.J. Cathcarta i R.P. Gordona: "Those who were delaying among you the times of your festivals I have removed from your midst. Woe to them, for they were taking up their arms against you and were reviling you"; K.J. C a t h c a r t, R.P. G o r d o n, The Targum of the Minor Prophets, The Aramaic Bible 14, Collegeville 1990, s. 173-174. 
Tekst w. 18 ze względu na różnice w manuskryptach nie jest do końca jasny również w wersji aramejskiej. Przeważa jednak opinia, że werset mówi o atakach wrogów narodu, którzy ingerowali w święta Izraela. נוגי (TM) Tamiast נוגימ (TMum czytał najprawdopodobniej יגה II - ,odepchnąć”, ,odsunąć”). Ponadto manuskrypty aramejskie potwierdzają zarówno wersję „biada” jak i „byli”. 25

Peszitta tłumaczy podobnie do LXX:

(17) כביומא דעדעדא (18) ואעבד מנכי עילין הוו דמלליך „,...jak w dzień święta. I usunę spośród ciebie tych, co mówili wstydliwe rzeczy o tobie". ${ }^{27}$

Wersje antyczne zasadniczo łączą pierwsze dwa wyrazy w. 18 z wersetem poprzedzejącym oraz są świadectwem różnego rozumienia tekstu hebrajskiego. Różność ta wynikała najprawdopodobniej z trudności tekstu oryginalnego a nie z różnorodności manuskryptów, które mieli przed sobą antyczni tłumacze.

\section{Propozycje rozwiązań}

Z próbą zrozumienia So 3,18 zmierzyli się nie tylko starożytni tłumacze. Współcześnie proponuje się wiele rozwiązań, które można pogrupować w zależności od tego, czy zmieniają tekst hebrajski,

25 Por. tamże, s. 173-174. Autorzy piszą ponadto: "Another version of $\mathrm{Tg}$. is quoted in $b$. Ber. 28a in the form: "Destruction is coming upon the enemies of the house of Israel because they delayed the times of the festivals in Jerusalem». R. Joshua ben Levi, to whom the quotation is attributed, explains MT $n w g y$ on the basis of Tg. tbr' («destruction»), which must have formed an integral part of Tg. as he knew it. But, since the words «the enemies of» are almost certainly euphemistic (cf. McCarthy, Tiqqune Sopherim 176f.), the talmudic version is dealing with members of the community itself who were guilty of tampering with festivals or set times of worship (cf. $T g$. Isa 24:5). R. Joshua ben Levi applied the verse to the Musaf Tefillah and to those who altered the times of festival prayers"; s. 174.

26 Por. J. V l a a r d i n g e r bro e k, Zephaniah, s. 211.

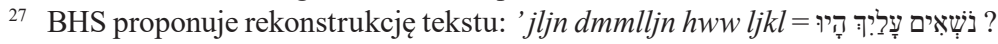


proponują nowe lub mniej znane rozumienie słów, różnią się w analizie syntaktycznej wersetu albo podchodzą do tekstu w sposób diachroniczny.

\section{Propozycje ingerujące $\mathrm{w}$ tekst hebrajski}

Wielu egzegetów próbowało tak zmienić tekst hebrajski So 3,18, by werset stał się bardziej czytelny. ${ }^{28}$

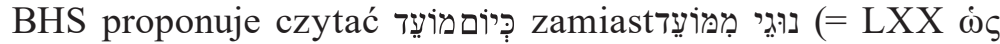

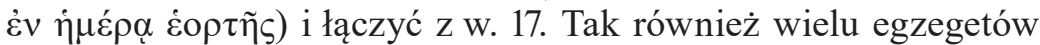
(np. Horst, Keller, Marti, Renaud, Seybold, J. Smith, R. Smith, Vlaardingerbroek ${ }^{29}$ ).

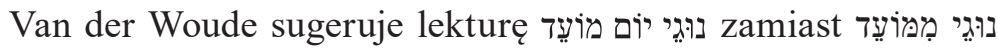
i tłumaczy „Z radością jak ta w dniu święta”. ${ }^{30}$ Podobnie Tsevat, który ponadto przyłącza te słowa do w. $17 .{ }^{31}$

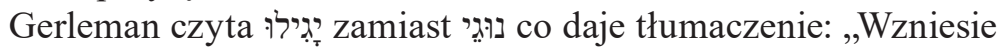
nad Tobą okrzyk radości: Radujcie się ze święta!"32

Sabbotka wokalizuje נוּגָ zamiast i נוּג i odwołuje się do ugaryckiego znaczenia „mijać się”, ,zboczyć z” (Qal passivum od נוג*). Ostatecznie daje to thumaczenie: „Tych, którzy odeszli ode mnie, zabieram ze wspólnoty". ${ }^{33}$

${ }_{28}$ Zebrane propozycje emendacji tekstu zob. J. V l a a r d i n g e r b r o e k, Zephaniah, s. 211-212, 215-216; H. I r s i 1 g e r, Zefanja, s. 422-423, 425-426; E. S á n d o r, Zofóniás. Filológiai kommentár, http://docplayer.hu/3897075-Zofonias-filologiaia -kommentar-enghy-sandor-2010.html (dostęp: 20 XI 2017).

29 J. V l a a rdinge rbroek, Zephaniah, s. 210 tłumaczy "as on a day of festival: I gather from among you who are (?) ... to bear disgrace on account of it".

30 Por. A.S. van der W o u d e, Habakuk. Zefanja, POT, Nijkerk 1978; nota za: J. V 1 a a rd in g e r b r o e k, Zephaniah, s. 211.

${ }_{31}$ Por. M. Ts e v a t, Some biblical notes, Hebrew Union College Annual 24/1952-1953, s. 111.

32 Por. G. G e rl e m a n, Zephanja: Textkritisch und literarisch untersucht, Lund 1942, s. 63.

33 „Die von mir gewichen raffte ich hinweg aus der Gemeinde”; L. S a b o t t k a, Zephanja: Versuch einer Neuübersetzung mit philologischem Kommentar, Roma 1972, s. 135. 
Deissler, Irsigler, Nötscher, Seybold, Sellin zamiast דָיו czytają הַוּה (,ruina”, ,zniszczenie”, ,groźby”) i tłumaczą: „usunę z ciebie przekleństwo, nieszczęście". ${ }^{34}$ Natomiast Elliger proponuje lekcję הַיוֹט oraz tłumaczenie ,odsunę od ciebie dzień znoszenia wyrzutów”. 35

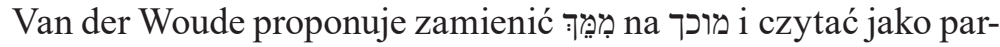
ticipium hofal czasownika מכך (,być uniżonym”, ,upokorzonym”), co daje tłumaczenie: ,zgromadzę upokorzonych”. ${ }^{36}$ Rudolph a za

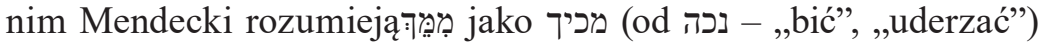
i tłumaczą ,zabiorę od ich prześladowców”.37

Smith za niektórymi wersjami antycznymi czyta עָּריָ (,na ciebie”)

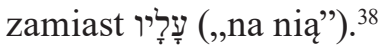

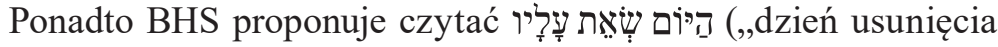
z niej"). Natomiast Ehrlich i Irsigler intepretują משת של משת (משת nie jako rze-

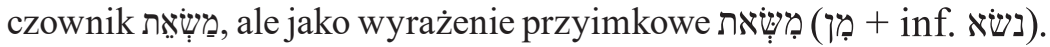

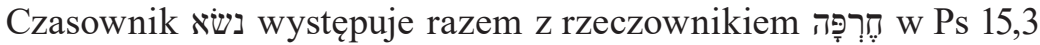

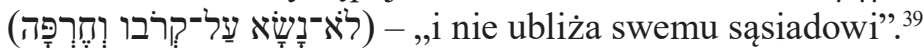

\section{Propozycje zależne od semantyki}

Niektórzy egzegeci proponują nie tyle zmienić tekst hebrajski, ile zrewidować znaczenie niektórych słów.

Smith interpretuje נוגי nie jako „zasmuconych”, ,zrozpaczonych”, lecz ,jako wydalonych”, „tych, którzy odeszli” i tłumaczy „ci, którzy

34 Por. H. I r si 1 g e r, Zefanja, s. 426.

35 Por. K. E 11 i g e r, Das Buch der zwölf kleinen Propheten, Göttingen 19797, S. 82 .

36 Nota za J. V l a a r d i ng e r b r o e k, Zephaniah, s. 212.

37 Por. W. Ru d ol p h, Micha, Nahum, Habakuk, Zephanja, Gütersloh 1975, s. 294. Mendecki tłumaczy w. 18 następująco: „Bolejących w oddaleniu od miejsc świętowania zabiorę od ich prześladowców, ponieważ z powodu mnie znosili hańbę"; N. M e n d e c k i, Koniec utrapień, s. 54.

38 Por. J.M.P. S m it h, A Critical and Exegetical Commentary on the Books of Micach, Zephaniah and Nahum, The International Critical Commentary, New York 1911, s. 262-263.

39 Por. H. I r silg e r, Zefanja, s. 426 
odeszli od święta". ${ }^{40}$ Podobnie tłumaczy Spreafico, chociaż widzi w nich nie mieszkańców diaspory, ale Izraelitów, którzy byli odrzucani przez innych ze względu na swoją wierności Bogu i praktykowanie sprawiedliwości. Odrzuceni i pogardzani są teraz wzywani do radości w Jeruzalem. ${ }^{41}$

Słowo מעוֹעָ bywa rozumiane nie tylko jako ,święto” (tak większość), ${ }^{42}$ ale również jako „oznaczony czas” (tak Sweeney), ${ }^{43}$ a nawet jako „wspólnota” (Wellhausen). ${ }^{44}$

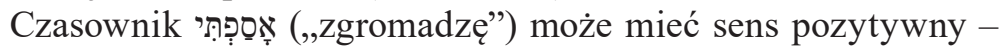
„zbierać, by wybawić” (Wellhausen ${ }^{45}$ ) lub negatywny „zbierać, by osądzić" (Sabbotka, Sweeney ${ }^{46}$ ). Kapelrud, a za nim Smith, Irsigler rozumieją czasownik אסף w znaczeniu ,zmieść”, ,usuwać”. ${ }^{47}$

Rzeczownik mię”, „ciężar” (tak większość), ale również jako „sygnał” (tak Ben Zvi). ${ }^{48}$

\section{Propozycje zależne od syntaksy}

So 3,18 zawiera kilka problemów syntaktycznych.

40 "Those who went away from the festival". Propozycja opiera się na użyciu czasownika הגָג w 2Sm 20,13 oraz na paralelach ugaryckich; por. R.L. S m it h, Micah-Malachi, s. 143.

${ }^{41}$ „Quelli che si sono separati dalla festa”; A. S p r e a f i c o, Sofonia, s. 199.

42 W tym też znaczeniu bliski So 3,18 jest Lm 1,4: „Drogi na Syjon w żałobie,

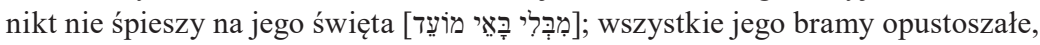
kapłani wzdychają, znękane $s q$ dziewice, on sam pogrążony w goryczy".

43 "Those who have suffered from the appointed time when I punished you were a burden upon her, a reproach"; M.A. S w e e n e y, Zephaniah, s. 204.

${ }^{44}$ „Die von der Gemeinde Versprengten habe ich gesammelt”; J. W e 11 h a u s e n, Die kleinen Propheten übersetzt und erklärt, Berlin 1893², s. 31, 155.

45 Por. tamíe.

46 Por. M.A. S w e e n e y, Zephaniah, s. 204.

47 "I have swept away from you”; R.L. S m it h, Micah-Malachi, s. 143; „Ich habe Unglück von dir weggenommen"; H. I r s i 1 g e r, Zefanja s. 425,429.

48 Por. E. B e n Z v i, A Historical Study of the Book of Zephania, Berlin 1991, s. 253; zob. Jr 6,1. 


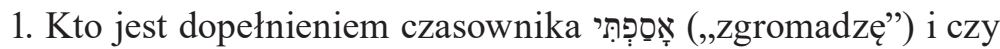

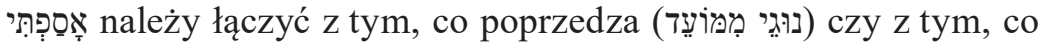

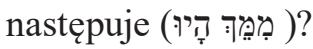

Ben Zvi proponuje lekturę, w której przedmiot (uciśnieni) poprzedza czasownik. ${ }^{49}$

2. Kto jest podmiotem czasownika הָּ i czy należy go łączyć z tym,

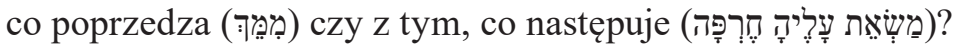

Według Smitha i Berlin zarówno to co poprzedza jak i to co na-

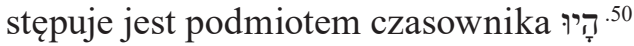

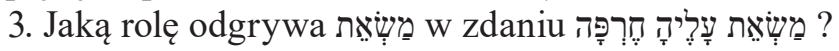

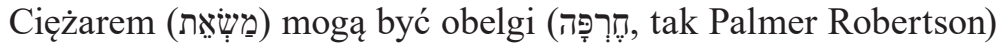
albo przez ciężar mogą być rozumiani uciskani (tak Sweeney).

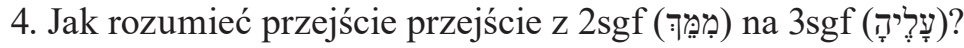

Wielu tłumaczy oba wyrażenie w 2sgf. Tak np. Biblia Poznańska („Usunę spośród ciebie zło, by nie ciążyła na tobie hańba”), Biblia Warszawsko-Praska („Kres kładę już twojej niedoli, uwalniam cię od pohańbienia”), Biblia Paulistów („Oddalę od ciebie nieszczęście, byś nie znosiła już hańby”), Einheitsübersetzung („Ich mache deinem Unglück ein Ende, ich nehme die Schmach von dir"), La Sacra Bibbia della Conferenza Episcopale Italiana („Io raccoglierò gli afflitti, privati delle feste e lontani da te. Sono la vergogna che grava su di te") czy The New International Version ("I will remove from you all who mourn over the loss of your appointed festivals, which is a burden and reproach for you").

49 "Those who are afflicted because they are deprived of the festivals I have gathered"; E. B e n Zv i, A Historical Study of the Book of Zephania, s. 253.

50 "Those who went away from the festival I have swept away from you They were heaping disgrace upon her"; R.L. S m it h, Micah-Malachi, s. 143; "Those grieving from the festival whom I have gathered were from you"; A. B e r 1 i n, Zephaniah, s. 141. 


\section{Propozycja diachroniczna}

Hadjiev zaproponował rozwiązanie diachroniczne problemu tekstualnego So $3,18 .^{51}$ Do tekstu oryginalnego Sofoniasza należałyby słowa נוגי ממועד אספתי משאת עליה חרפה rozumiane w sensie: „Zbiorę usuniętych ze zgromadzenia, ponieważ dźwigali dla niego obelgi”. Następnie została dodana glossa ממך היו oni są [daleko] od ciebie”, wyjaśniająca relację omawianych protagonistów do Boga. Na ostatnim etapie, skryba dopisał w. 19 i wstawił glossę do tekstu w celu lepszego połączenia zakończenia księgi (So 3,18-20) z poprzedzającą ją częścią. Problematyczność w. 18 wynikałaby więc z różnych etapów i celów redakcyjnych. ${ }^{52}$

$$
* * *
$$

O czym zatem mówi So 3,18? Czy mówi o uciśnionych, którzy cierpieli od pewnego czasu z powodu Dnia Jahwe, sądu koniecznego, aby oczyścić grzechy Jerozolimy (M.A. Sweeney)? A może mówi o zasmuconych wygnańcach, którzy wierni Bogu cierpieli z powodu braku świąt i byli prześladowani, lecz teraz Bóg już się za nimi ujmie (N. Mendecki)? Czy może jednak chodzi o grzeszników, których Bóg usunie z Jeruzalem, gdyż przynosili oni miastu tylko hańbę (R. Smith)? Albo to obietnica, że Bóg usunie tych, co pokonali Jeruzalem i przynieśli jej wstyd (J. Smith)? A może rację ma Targum, mówiąc o tych, którzy zostaną ukarani, bo przynieśli hańbę miastu opóźniając święta? Na obecnym etapie stanu wiedzy, jaką posiadamy, nie możemy jednoznacznie ustalić, o co tak naprawdę chodzi w So 3,18. Natomiast wnioski, które nasuwają się po analizie

51 Por. S.T. H a d j i e v, The Translation Problems of Zephaniah 3,18: A Diachronic solution, Zeitschrift für die alttestamentliche Wissenschaft 124/2012, s. 416-420.

52 "The problems resulted largely from the insertion of the phrase «they are (far away) from you» $(3,18 \mathrm{a} ß)$ by an editor who also composed 3,19 in order to tie in the conclusion of the book (3,18-20) to the preceding passage"; tamże, s. 420. 
tego wersetu, można by zapewne odnieść do wielu crux interpretum Biblii, a są one następujące:

1. Mimo wielu propozycji zmierzenia się z trudnościami So 3,18, nie ma zasadniczo nadziei na znalezienie satysfakcjonującego rozwiązania.

2. Przykład So 3,18 rodzi pytanie o sens kolejnych badań. I o ile analiza jest zasadna z puntu widzenia poznawczego (egzegeta nabywa wiedzy) i intelektualnego (egzegeta ćwiczy swoją kreatywność), to jednak trudno znaleźć zasadność kontynuowania badań nad sprawą wielokroć oraz bezskutecznie przebadaną.

3. So 3,18 jest przykładem zjawiska zapisywania interpretacji jako tekstu biblijnego. Egzegeci proponujący swoje tłumaczenia, bardzo często różniące się od siebie, są jednocześnie twórcami tekstu, który nazywają tekstem biblijnym. Dlatego rodzi się pytanie o definicję Biblii. Można postawić tezę, że Pismo Święto jest pojęciem abstrakcyjnym, natomiast konkretny tekst biblijny (jeden z manuskryptów lub przekładów) partycypuje mniej lub bardziej w pojęciu ogólnym. Używając metafory, można powiedzieć, że teksty biblijne mają się tak do Biblii jak ludzie do pojęcia człowieka.

4. So 3,18 jest przykładem kenotycznego charakteru słowa Bożego, Bóg chciał przemówić do ludzi przez ludzi. Zgodził się, by Jego doskonałe słowo wyraziło się w niedoskonałym słowie człowieka. Ta niedoskonałość ludzkiego słowa względem Bożej prawdy rozumiana jest nie tylko jako wynikająca z natury niemożność ogarnięcia przez człowieka tego, co boskie, ale również jako przyjęcie ludzkich błędów, niejasności, od których nie jest wolny nawet natchniony biblijny autor. Księga Sofoniasza, jak i cała Biblia, jest wystarczająco klarowna, by pojąć Boże objawienie, i wystarczająco trudna, by zobaczyć pokorę słowa Boga, które stało się słowem ludzkim. 
Słowa kluczowe: Sofoniasz, So 3,18, krytyka tekstu, egzegeza, przekład Keywords: Zephaniah, Zeph. 3:18, textual criticism, exegesis, translation

\section{Textual, Exegetical and Translatory Problems of Zeph. 3,18 \\ Summary}

The aim of this paper is to analyze Zeph. 3,18, one of the most incomprehensible verses in the book. Firstly, the author describes the near context of the verse, then he examines some variants of the Hebrew manuscripts and the ancient versions. In the next section he presents all the possible solutions dividing them into four groups: 1) based on an emendation of the text; 2) based on semantics, 3) based on its syntax, 4) a diachronic solution. In the conclusion, the author suggests four notions to be applied probably to several instances of crux interpretum of the Bible. 